\title{
Unknown primary Merkel cell carcinoma with cutaneous spread
}

\author{
João Vasco Barreira, ${ }^{1}$ Margarida Moura Valejo Coelho, ${ }^{\bullet 2}$ Catarina Ribeiro, ${ }^{3}$ \\ Mónica Semedo ${ }^{4}$
}

${ }^{1}$ Medical Oncology, Hospital de Santo Antonio dos Capuchos, Lisboa, Portugal

'Dermatology and Venereology, Centro Hospitalar de Lisboa Central, Lisboa, Lisboa, Portugal ${ }^{3}$ Universidade de Coimbra Faculdade de Medicina, Coimbra, Coimbra, Portugal ${ }^{4}$ Medical Oncology, Hospital Distrital De Santarem Epe, Santarem, Santarém, Portugal

\section{Correspondence to}

Dr João Vasco Barreira, joaovascobarreira@gmail.com

JVB and MMVC contributed equally.

Accepted 6 February 2019

\section{SUMMARY}

The authors present the case of a woman in the seventh decade of life with medical history of: left nephrectomy for renal tuberculosis and non-Hodgkin's lymphoma treated with chemotherapy (QT) and radiotherapy. She presented with a 2-month history of non-tender, left inguinal lymph node enlargement. Positron Emission Tomography $(\mathrm{PET})=\mathrm{CT}$ - scanshowed hypermetabolic inguinal and retroperitoneal lymphadenopathies, no primary tumour. On the second dermatological examination a pink, $2 \mathrm{~cm}$ plaque on the anterior left knee was noted. The histopathological analysis revealed Merkel cell carcinoma. The patient underwent two lines of systemic QT, with life-threatening toxicities limiting treatment. Followed overwhelming disease progression with lymphoedema and numerous skin metastases in the left lower limb. The patient received palliative care until death. The rare incidence of such neoplasia and its uncommon clinical presentation justifies reporting this case and highlights the importance of multidisciplinary teams in the management of cancer patients.

\section{BACKGROUND}

This uncommon clinical presentation of Merkel cell carcinoma (MCC) in addition to its rare incidence justifies the utmost importance of publishing the case.

As more cases of unknown primary MCC (UPMCC) are reported in the literature, further characterisation of the tumour and determination of prognostic factors will become possible through combined analysis of these cases.

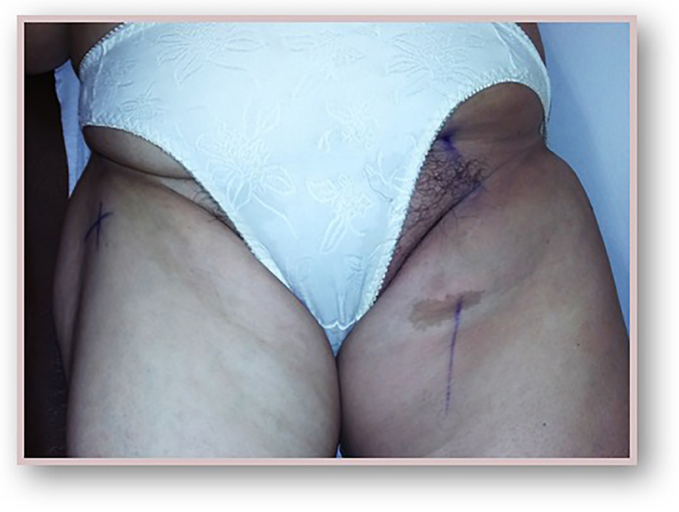

Figure 1 Non-tender, left inguinal lymph node enlargement at presentation (April 2015).

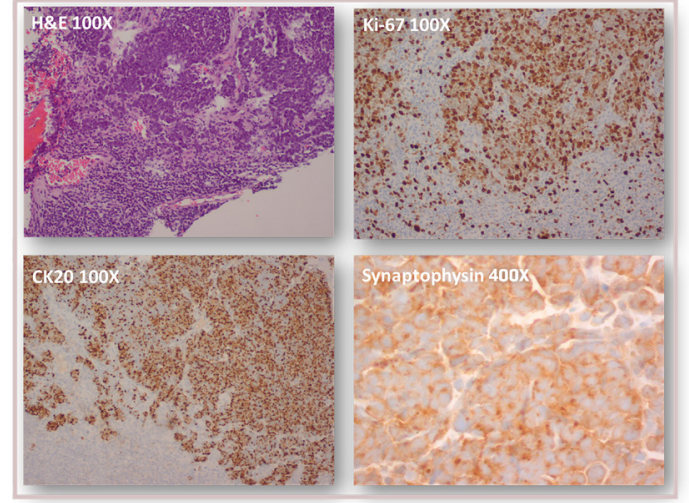

Figure 2 Histopathological findings in ultrasoundguided biopsy of left inguinal adenopathy: lymph node metastasis of a carcinoma with neuroendocrine differentiation (CK20+, synaptophysin+, CK7-, E-cadherin+) and high proliferative index (Ki-67 approximately 100\%).

\section{CASE PRESENTATION}

We present a case of a woman in the seventh decade of life with medical history of: left nephrectomy for renal tuberculosis in the third decade of life, and non-Hodgkin's lymphoma of the right breast treated with chemotherapy (QT) and radiotherapy (RT) 12 years beforehand. The presenting feature was a 2-month history of non-tender, left inguinal lymph node (LN) enlargement (figure 1). An ultrasound-guided biopsy revealed LN metastasis of a carcinoma with neuroendocrine differentiation and high proliferative index-approximately 100\%. (figure 2). On the first dermatological examination (April) no mucocutaneous suspicious lesions were found. The CT scan found large, conglomerate $\mathrm{LN}$ on the left inguinal and obturator basins. The PET-CT scan showed hypermetabolic inguinal and retroperitoneal lymphadenopathies but no primary tumour (figure 3). RT was done to the inguinal nodes with good response. On the second dermatological examination (4 months later, in August), a non-tender, pink, infiltrated, $2 \mathrm{~cm}$ plaque on the anterior surface of the left knee was found (figure 4). The histopathological findings of a biopsy of the lesion were compatible with metastases of an MCC of unknown primary location (figure 5).

\section{OUTCOME AND FOLLOW-UP}

At this point, the patient begun systemic QT. The first line was cisplatin and etoposide with 


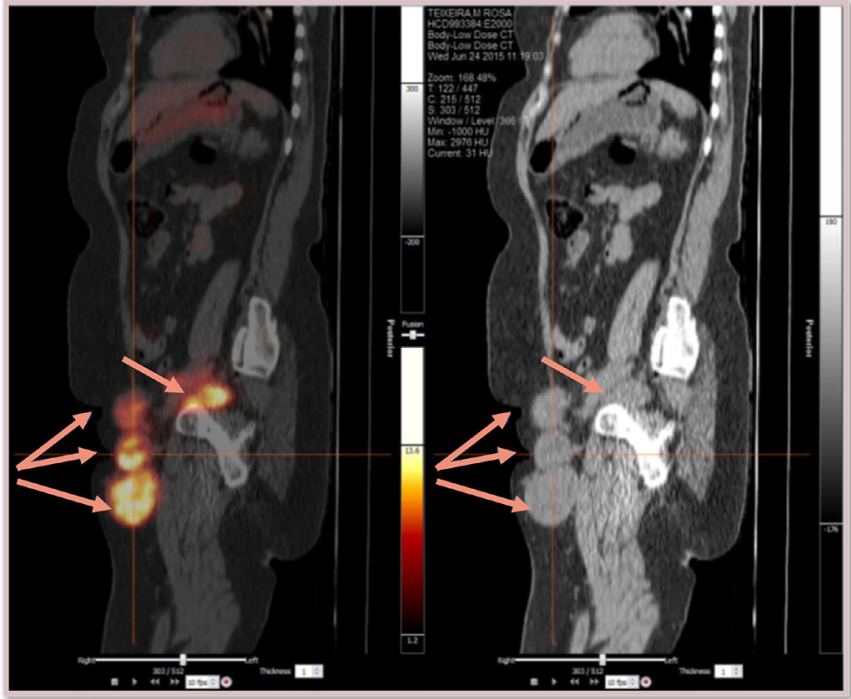

Figure 3 PET-CT scan (sagittal): large, hypermetabolic inguinal and retroperitoneal lymphadenopathies; no primary tumour identified.

remarkable clinical and imaging response, but grade 3 kidney failure. This lead to changing to a second line (topotecan) with also clinical stable disease response, but grade 3 pancytopenia. These life-threatening toxicities limited treatment in both QT attempts. Overwhelming disease progression followed treatment suspension, with lymphoedema and numerous skin metastases on the left lower limb (figure 6). The patient received palliative care until death.

\section{DISCUSSION}

Knowledge regarding UPMCC is limited. It is still unclear whether its origin represents regional nodal involvement from an undetected and spontaneously regressed MCC, or a de novo development on the LN itself.

As MCC is such a rare and a challenging disease, treatment approaches should always be discussed in a multidisciplinary team and considered individually, in light the existing evidence

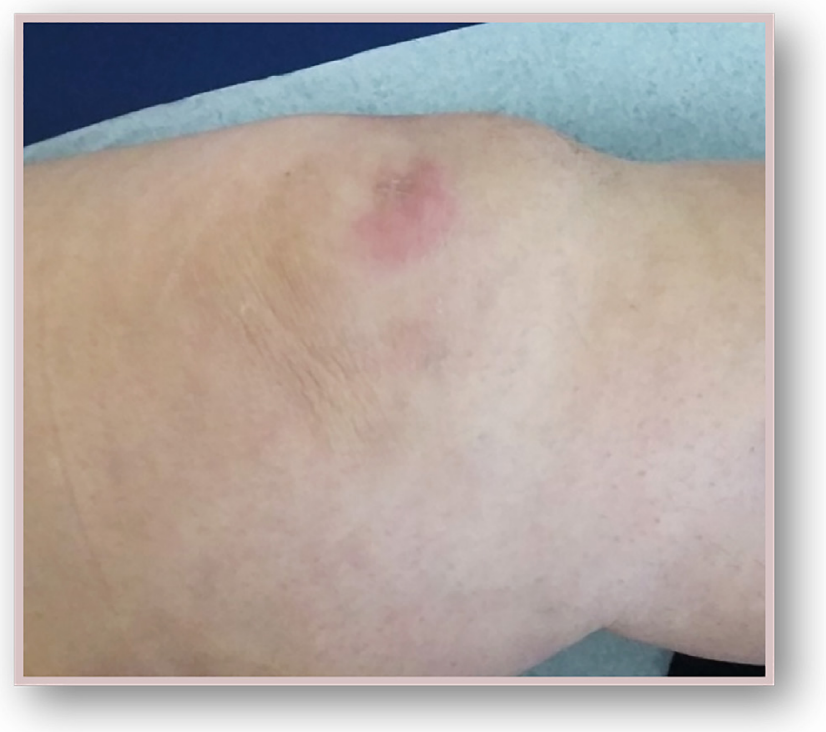

Figure 4 Non-tender, pink, infiltrated, $2 \mathrm{~cm}$ plaque on the anterior surface of the left knee (August 2015).

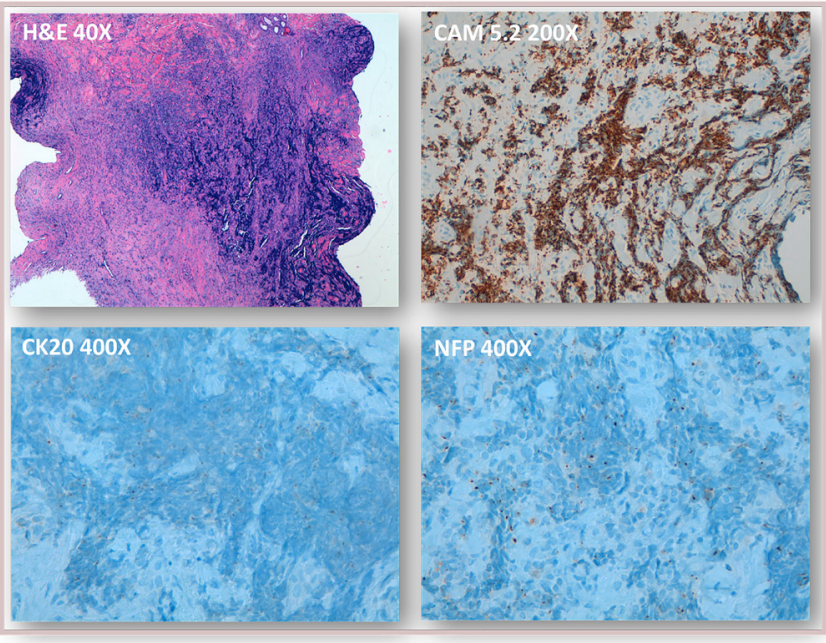

Figure 5 Histopathological findings in skin lesion biopsy (left knee): dense nests and cords of atypical basaloid cells infiltrating the dermis and hypodermis, staining positive for CK20, CAM5.2 and neurofilaments in a paranuclear dot-like pattern, and negative for CK7, S100 and TTF1 -findings compatible with Merkel cell carcinoma.

combined with a reference centre expertise. The case reported by Muus Steffensen $\mathrm{S}$ et al is a good example of a patient with MCC treated with multimodal approaches (in this case, conservative surgery and adjuvant RT) allowing a combination of patient's preferences, available treatments and evidence. ${ }^{1}$

Similarly to this case, in literature we found that a substantial number of patients with UPMCC have a positive oncologic history. ${ }^{2}$ As its natural history is unpredictable, a multidisciplinary consultation at a centre with significant MCC expertise, including dermatology, medical oncology, radiation oncology and surgery, is in the best interest of the patient. ${ }^{34}$ UPMCC is probably best treated as stage III/IV MCC.

There are recent studies that have shown that UPMCC have an improved survival outcome. However, there are limited evidence to support that fact $^{267}$. In our case, the patient did not have sustained response to the treatment and overwhelming disease progression was seen.

Until 2016, before the introduction of immunotherapy, the most common treatments for metastatic MCC were chemotherapeutic regimens often used for other small-cell carcinomas. These include platinum-based regimens, etoposide, taxanes and anthracyclines, either alone or in various combinations. ${ }^{8}$ These treatments led to clinically meaningful responses in a subset of patients; however, these responses were short-lived, as we demonstrated in our clinical case.

Histopathological characterisation could have helped to direct the treatment in this specific case. Striking data indicate that checkpoint inhibitors, antibodies targeting the inhibitory programmed cell death protein 1 (PD-1) receptor or its ligand (PD-L1), are effective in MCC. This suggests MCC is a highly immunosensitive malignancy. In 2017, Avelumab became the first drug approved by the US Food and Drug Administration for MCC. Pembrolizumab and nivolumab have shown similar efficacy in metastatic disease, and their approval in this setting is a certainty. Although there are no head-to-head trials comparing checkpoint inhibitors with CT, the results of this new immunotherapy-based approach compare favourably with historical data for CT in advanced MCC, especially in terms of safety features and durability of response. ${ }^{9-11}$ 

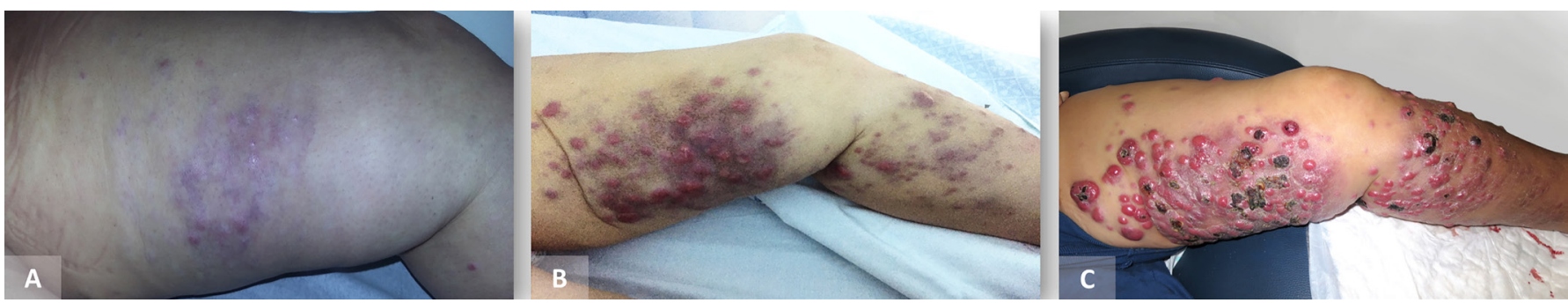

Figure 6 Disease progression after therapy discontinuation: (A) Emergence of skin metastases in the left inner thigh weeks after stopping radiotherapy to the inguinal basin (September 2015). (B,C) Numerous skin metastases and lymphoedema in the left lower limb after discontinuation of chemotherapy (March 2016).

The rising role of systemic immunotherapy in cancer is illustrated in a case reported by O'Brien $\mathrm{T}$ et al. ${ }^{12}$ The rationale for immunotherapy in MCC is based on the aetiology of this disease. In 2008, Feng et al described an oncogenic Merkel cell polyomavirus, present in about $80 \%$ of MCC tumours. This polyomavirus creates a large $\mathrm{T}$ antigen that inactivates tumour suppressors p53 and retinoblastoma protein. This discovery not only identified a causative factor for MCC, but also suggested a role for immune evasion in MCC's oncogenesis. ${ }^{13} 14$

Despite major advances in the understanding of the carcinogenesis, biology and immunology of MCC, as well as the breakthrough in the therapy of advanced-stage disease using immune-checkpoint inhibitors, much work remains. Further characterisation of this tumour is crucial for determining prognostic factors and defining optimal treatment. Ongoing clinical trials of immune-checkpoint inhibitors for MCC combine multiple treatment strategies to avoid or to overcome immune escape mechanisms. ${ }^{15}$

\section{Learning points}

- Merkel cell carcinoma (MCC) is an uncommon and highly aggressive cutaneous neoplasm with neuroendocrine differentiation.

- Although MCC typically presents as a rapidly growing asymptomatic skin nodule, some rare patients have nodal presentation with no identified primary tumour.

- By reporting the case of an advanced MCC presenting with extensive lymph node involvement prior to cutaneous manifestations, the authors aim to discuss this rare form of disease and highlight the importance of multidisciplinary teams in the management of cancer patients. As new data emerge about immunotherapies targeting the programmed cell death protein 1/ligand (PD-L1) pathway, the potential expression of PD-L1 in the MCC tumour microenvironment is of increasing interest.

- Combined analysis may also permit the definition of optimal treatment considering the rarity of this tumour.
Contributors JVB and MMVC developed and took the lead in writing the manuscript. CR and Mós provided critical feedback and helped shape the manuscript. All authors agreed with the final version of the manuscript.

Funding The authors have not declared a specific grant for this research from any funding agency in the public, commercial or not-for-profit sectors.

Competing interests None declared.

Patient consent for publication Not required.

Provenance and peer review Not commissioned; externally peer reviewed.

\section{REFERENCES}

1 Muus Steffensen S, Korsgaard N. Shared decision-making in treatment of Merkel cell carcinoma. BMJ Case Rep 2014;2014:doi: bcr2013201675.

2 Tarantola TI, Vallow LA, Halyard MY, et al. Unknown primary Merkel cell carcinoma: 23 new cases and a review. J Am Acad Dermatol 2013;68:433-40.

3 NCCN Guidelines: Merkel Cell Carcinoma. Version 2018;2.

4 Haymerle G, Fochtmann A, Kunstfeld R, et al. Management of Merkel cell carcinoma of unknown primary origin: the Vienna Medical School experience. Eur Arch Otorhinolaryngol 2015;272:425-9.

5 Foote M, Veness M, Zarate D, et al. Merkel cell carcinoma: the prognostic implications of an occult primary in stage IIIB (nodal) disease. J Am Acad Dermatol 2012;67:395-9.

6 Chen KT, Papavasiliou P, Edwards K, et al. A better prognosis for Merkel cell carcinoma of unknown primary origin. Am J Surg 2013:206:752-7.

7 Deneve JL, Messina JL, Marzban SS, et al. Merkel cell carcinoma of unknown primary origin. Ann Surg Oncol 2012;19:2360-6.

8 Nghiem P, Kaufman HL, Bharmal M, et al. Systematic literature review of efficacy, safety and tolerability outcomes of chemotherapy regimens in patients with metastatic Merkel cell carcinoma. Future Oncol 2017:13:1263-79.

9 Topalian SL, Bhatia S, Kudchadkar RR, et al. Nivolumab as neoadjuvant therapy in patients with resectable Merkel cell carcinoma in CheckMate 358. ASCO Annual Meeting 2018. Abstract 9505.

10 Nghiem P, Bhatia S, Brohl AS, et al. Two-year efficacy and safety update from JAVELIN Merkel 200 part A: A registrational study of avelumab in metastatic Merkel cell carcinoma progressed on chemotherapy. ASCO Annual Meeting 2018. Abstract 9507

11 Nghiem P, Bhatia S, Lipson EJ, et al. Durable tumor regression and overall survival in patients with advanced merkel cell carcinoma receiving pembrolizumab as first-line therapy. J Clin Oncol 2019:JC0.18.01896. Abstract 9506.

12 O'Brien T, Power DG. Metastatic Merkel-cell carcinoma: the dawn of a new era. BMJ Case Rep 2018:2018:bcr-2018-224924

13 Feng $\mathrm{H}$, Shuda M, Chang Y, et al. Clonal integration of a polyomavirus in human Merkel cell carcinoma. Science 2008;319:1096-100.

14 Bhatia S, Afanasiev O, Nghiem P. Immunobiology of Merkel cell carcinoma: implications for immunotherapy of a polyomavirus-associated cancer. Curr Oncol Rep 2011;13:488-97.

15 Terheyden P, Becker JC. New developments in the biology and the treatment of metastatic Merkel cell carcinoma. Curr Opin Oncol 2017;29:221-6. 
Copyright 2019 BMJ Publishing Group. All rights reserved. For permission to reuse any of this content visit https://www.bmj.com/company/products-services/rights-and-licensing/permissions/

BMJ Case Report Fellows may re-use this article for personal use and teaching without any further permission.

Become a Fellow of BMJ Case Reports today and you can:

- Submit as many cases as you like

- Enjoy fast sympathetic peer review and rapid publication of accepted articles

Access all the published articles

- Re-use any of the published material for personal use and teaching without further permission

For information on Institutional Fellowships contact consortiasales@bmjgroup.com

Visit casereports.bmj.com for more articles like this and to become a Fellow 